\title{
T促 \\ PERFORMANCE ANALYSIS OF FUZZY \\ CONTROLLER BASED ZVS DC-DC \\ CONVERTER FOR SOLAR ENERGY \\ CONVERSION SYSTEM
}

\author{
Abhishek Deshwal ${ }^{1}$, Vinod Kumar Yadav $^{2}$ \\ E-Mail id: mr.abbishek.deshwal111@gmail.com \\ Department of Electrical Engineering, CTAE, Udaipur, Rajasthan (India)
}

\begin{abstract}
This present work emphasis on the improvement of resonant converter (DC -DC converter) for solar energy conversion system (SECS). It accentuations on plan and exhibiting periods of the distinctive constituents of the SECS like the rudimentary model of zero voltage switching (ZVS) converter, inverter, fuzzy logic controller, best maximum power point tracking (MPPT) system utilizing MATLAB/ Simulink. Here, a resonant converter represents the static and dynamic characteristics of an actual solar irradiance have been developed for simulation tests. The irradiance and temperature changes circumstances are performed using the resonant converter, which consist of PV system, whose control is implemented using Fuzzy logic control unit and MATLAB/ Simulink. This PV module can achieve maximum power using Perturb \& Obserb algorithm. Under various abnormal conditions like change in irradiance and temperature, step change in irradiance etc. The control system is executed on a fuzzy logic control unit. Speculative outcomes are exhibited utilizing a 200W model of SECS to demonstrate the better aftereffects of the propelled framework and their control under steady- state and dynamic conditions.
\end{abstract}

Index Terms- Soft Switching techniques, Maximum Power Point Tracking (MPPT), Fuzzy logic controller (FLC), Zero voltage switching (ZVS), Photo voltaic array (PV array).

\section{INTRODUCTION}

This present work is for the most part worry towards applying delicate switching strategies for converter which is useful for Photo-Voltaic vitality conversion framework. The goal is to diminish switching losses by utilizing a resounding circuit with ordinary Buck converter. To affirm profoundly productive activity of photograph voltaic (PV) module, maximum power point tracking (MPPT) calculation is utilized for most extreme extraction of intensity. IGBT's are worked in the lower repeat reach out (up to $100 \mathrm{kHz}$ ) anyway MOSFET's are worked at generously higher repeat run appeared differently in relation to IGBT. The anticipated converter is worked under zero current switching (ZCS) and zero voltage switching (ZVS) condition which ensures upgraded capability, less electromagnetic impediment, etc.

\subsection{Losses in Switching Devices}

The gadgets utilized for switching in converters does not act as perfect in exploratory circumstances, henceforth they are wellsprings of loss of vitality in the framework. These losses are of two kinds which are portrayed beneath that are conduction losses and switching losses.

\subsection{Soft Switching}

The challenges if there should arise an occurrence of hard switching like switching misfortunes, EMI, current and voltage stresses can be decreased by utilizing the delicate switching strategy. ZVS and ZCS are the two switching systems. As on account of MOSFET, it comprises of capacitance C ds which is basically a mix of interior capacitance with extra outer capacitance. MOSFET can be turned on when it is certain that voltage over the switch just before the turned on is zero and MOSFET can turnoff with ZVS in light of Cds which keeps away from a sudden ascent in the voltage as the gadget is turn-off.

\section{PROPOSED METHOD FOR RESONANT CONVERTER}

In this section, modeling of different components of the proposed resonant converter (DC -DC converter) based SECS are presented in detail. Here, a resonant converter represents the static and dynamic characteristics of an actual solar irradiance have been developed for simulation tests. The irradiance and temperature changes circumstances are accomplished using the resonant converter, which comprise of PV system, whose control is implemented using Fuzzy logic control unit and MATLAB/ Simulink. This PV module can achieve maximum power using Perturb \& Obserb algorithm and fuzzy logic controller.

\subsection{Arrangement of Proposed PV System}

The PV framework with MPPT by utilizing ZVS is appeared in the Fig. 2.1. The yield voltage and current DOI Number: https://doi.org/10.30780/IJTRS.V04.I08.005

pg. 25 


\section{7 - $R$ S International Journal of Technical Research \& Science}

of PV is given to the converter and ZVS based MPPT square which thus set the duty cycle of pulses to extract the maximum power.

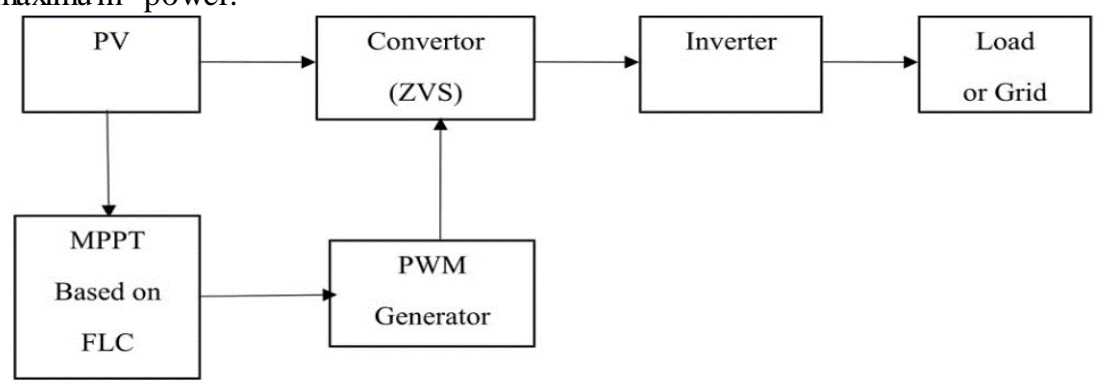

Fig. 2.1 Block Diagram of PV Standalone System with ZVS

2.2 MPPT fuzzy Logic-Based

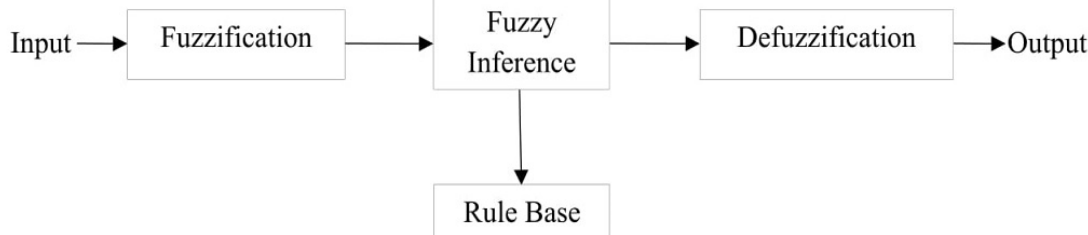

Fig. 2.2 Block Diagram of Fuzzy Control Unit

In the MPPT control, FLC is utilized to decide the duty cycle of the buck convertor. When all is said in done, the contribution on the FLC is error value (E) and modification in error ( $\triangle \mathrm{E})$ at test time k, anyway the yield of FLC is the yield voltage (V) and power (P).

2.1

$$
E(k)=P(k)-P(k-1) \div V(k)-V(k-1)
$$

2.2

$$
\Delta E(k)=E(k)-E(k-1)
$$

Five fluffy dimensions are utilized for all the info and yield variable. NS (negative little), NB (negative enormous), ZE (zero), PS (positive little) and PB (positive huge). The control rules are demonstrated in Table- 2.1.

\begin{tabular}{|c|c|c|c|c|c|c|}
\hline$\Delta \mathbf{E}(\mathbf{K}) / \quad \dot{\mathbf{E}}(\mathbf{k})$ & NB & $\mathbf{N S}$ & $\overline{\mathbf{Z E}}$ & $\mathbf{P S}$ & PB & \\
\hline $\mathrm{NB}$ & $\overline{\mathrm{PB}}$ & $\overline{\mathrm{PB}}$ & $\overline{\mathrm{PS}}$ & $\overline{\mathrm{PS}}$ & PS & \\
\hline NS & $\mathrm{ZE}$ & $\overline{\mathrm{ZE}}$ & $\overline{\mathrm{PS}}$ & PS & PS & \\
\hline $\mathrm{ZE}$ & NS & $\mathrm{NS}$ & $\overline{Z E}$ & PS & PS & \\
\hline PS & NS & $\overline{\mathrm{NS}}$ & $\mathrm{NS}$ & $\overline{\mathrm{ZE}}$ & $\overline{\mathrm{ZE}}$ & \\
\hline PB & NB & $\mathrm{NB}$ & $\mathrm{NS}$ & $\mathrm{NS}$ & $\mathrm{NS}$ & \\
\hline
\end{tabular}

Table-2.1 Fuzzy Rule Base for MPPT

One $\mathrm{E}$ and $\Delta \mathrm{E}$ are purposeful, they are changed into etymological factors and after that the yield is created by after defuzzification. The centroid technique is utilized for defuzzification due to its great averaging properties.

\subsection{MPPT Control for PV System}

In $\mathrm{P} \& \mathrm{O}$ strategy, the purpose of the past annoyance and the purpose of the past addition in the power are utilized to choose what the following irritation ought to be on the left of MPP augmenting the voltage cause builds the power while on the privilege decrementing the voltage cause expands the power.
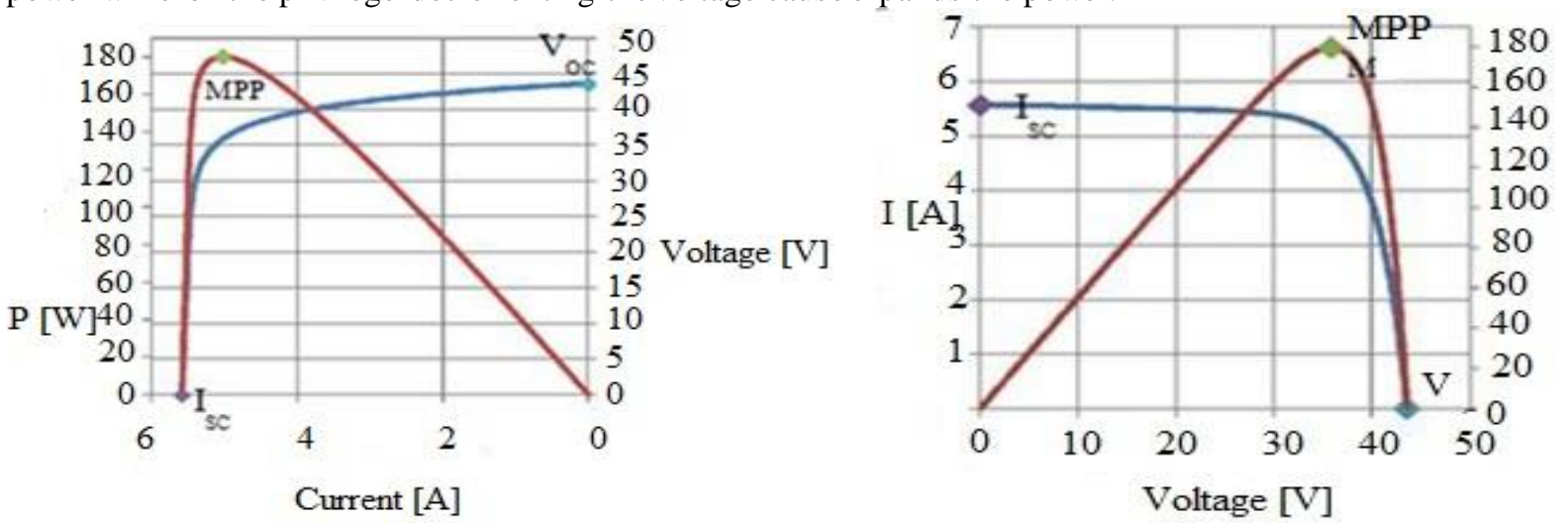

Fig. 2.3 PV Panel Characteristic Curves

DOI Number: https://doi.org/10.30780/IJTRS.V04.I08.005

pg. 26

www.ijtrs.com

www.ijtrs.org

Paper Id: IJTRS-V4-I8-004 


\section{J I R SInternational Journal of Technical Research \& Science}

On the off chance that there is an addition in the power, the irritation ought to be kept a similar way and on the off chance that the power diminishes, the following bother ought to be the other way. On Basis of these certainties, the calculation is connected. This irritation technique is intermittent until the point when the MPP isn't obtained. At that point the working point vacillates about the MPP. Same constant irritation reprobate is basic likewise to the INC technique, as was notice prior. A plan of the calculation is appeared in Fig.2.3.

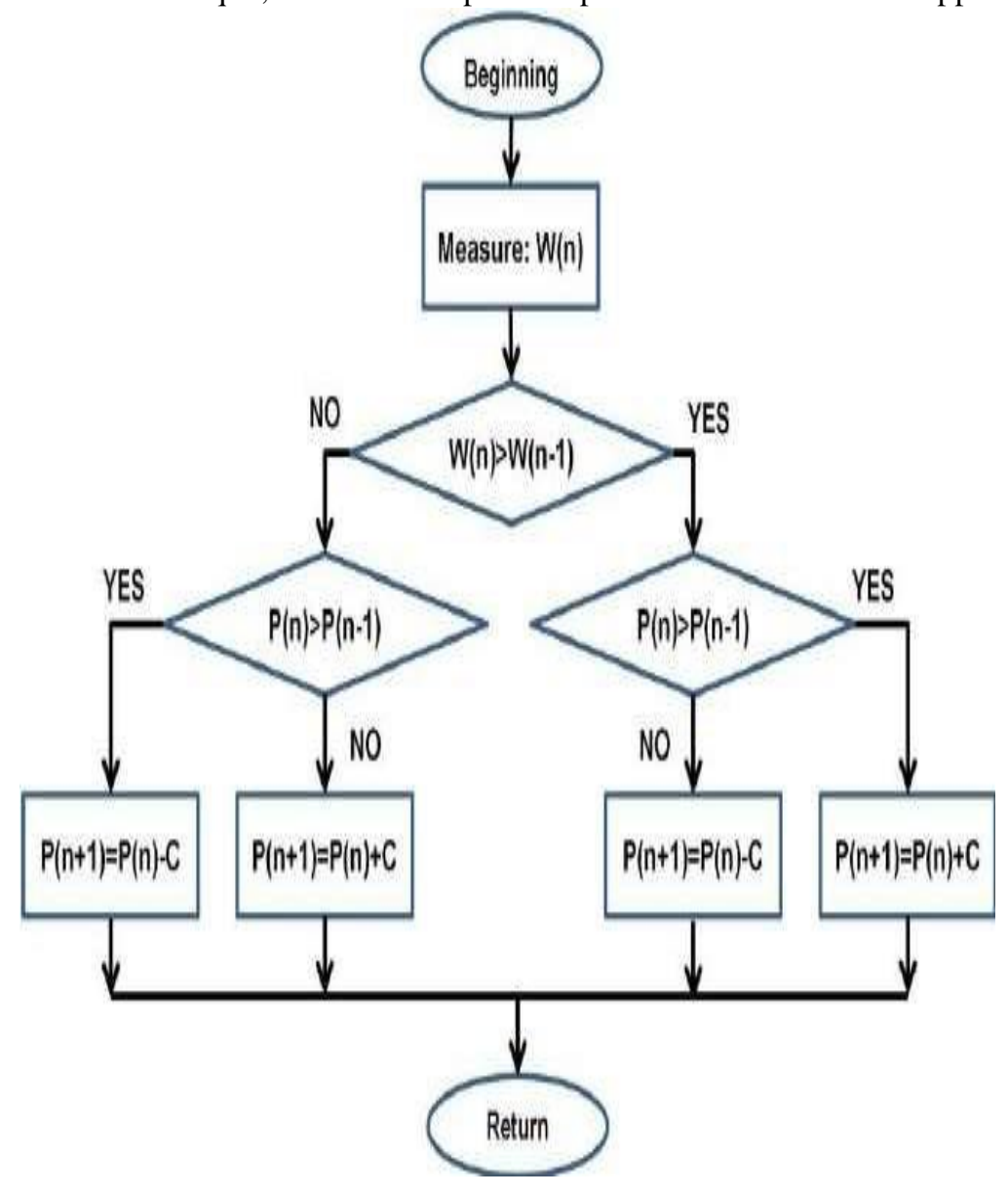

Fig. 2.4 Flow Chart P \&O Method MPPT

\section{MATHEMATICAL MODELING OF RESONANT CONVERTER}

This section contributes a thought on soft-switching buck converter. There are numerous DC-DC converters exist. What's more, the buck converter utilizing delicate switches make the entire framework increasingly powerful. How it builds the capability of framework and detail dialog on soft-switching strategies.

\subsection{Simulation of the converter}

The converter used in this circuit is simulated in matlab2015a environment by taking this component specification.

Table 3.1: Components Specification for Simulation

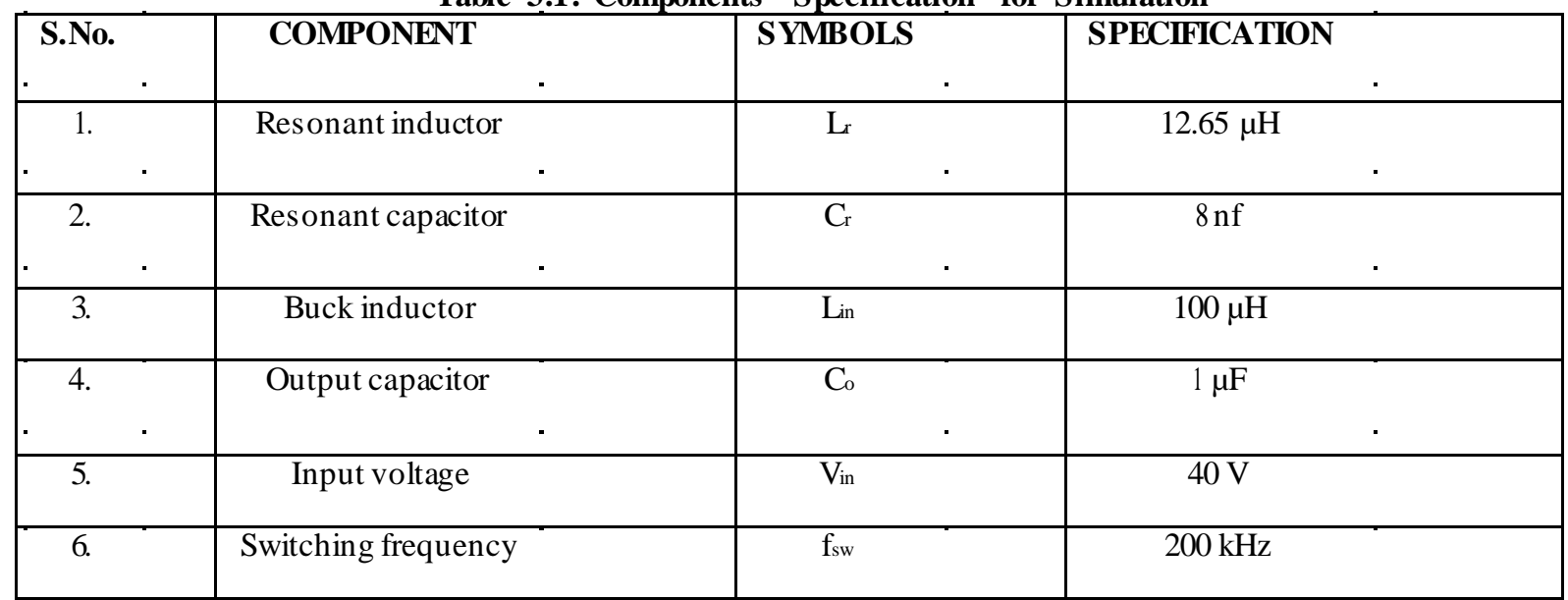




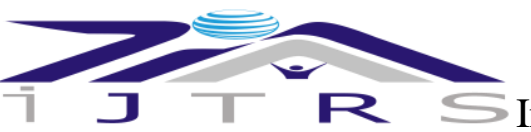 3.2 Loss Calculation and Comparative Study}

In order to pass on the relative investigation, a traditionalist hard switching converter is purposeful for similar stipulations. A buck converter with the constituent qualities is reproduced and the losses of both the converters are thought about.

$$
\mathrm{P}=\mathrm{V}_{0} \times \mathrm{I}_{0} \times \mathrm{F}_{\mathrm{sw}} \times \frac{\mathrm{T}_{\text {on }}+\mathrm{T}_{\text {off }}}{2}
$$

\subsubsection{Losses in the Soft Switching Converter}

Under zero voltage condition the fundamental switch's turn-on and changeover happens. Hence, from the above recipe the switching losses of the main switch amid turn-on are zero.

$$
P_{\text {swon }}=0 \mathrm{~W}
$$

The fundamental turn-off changeover happens at decreased voltage and the voltage amid turn-off is estimated and is observed to be $40 \mathrm{~V}$ and the pinnacle current through this change is estimated to be $4 \mathrm{~A}$.

The turning losses amid turn-off time are determined as same however for this situation voltage cross the switch is likewise zero so the switching loss of the main turn-off is zero.

$$
P_{\text {swoff }}=0
$$

The total switching losses are:

$$
\mathrm{P}_{\mathrm{sw}}=\mathrm{P}_{\text {swon }}+\mathrm{P}_{\text {swoff }}=0+0=0 \mathrm{~W}
$$

The conduction losses of the switches are conscious utilizing the equation. The RMS current of the main change is estimated to be 2.82 Amperes and the conduction losses are determined as pursues

$$
\mathrm{P}_{\text {cond_sw }}=1.8 * 2.822 * 0.85=12.16 \mathrm{~W}
$$

The conduction losses of the diode are result of the forward voltage drop (VF) over the diode and the normal current (ID) coursing through it. The current through it is the load current that is 0.625 Amperes and voltage drop is 0.8027 Volt. In this manner, the conduction losses of the diode are determined as.

$$
\mathrm{P}_{\text {cond_ Diode }}=\mathrm{V}_{\mathrm{F}} * \mathrm{ID}_{\mathrm{D}}=0.8027 * 0.625=0.5016
$$

The total losses in the converter are:

$\mathrm{P}_{\text {losses }}=\mathrm{P}_{\mathrm{sw}}+\mathrm{P}_{\text {cond_sw }}+\mathrm{P}_{\text {cond_Diode }}$

$$
\mathrm{P}_{\text {losses }}=0+4.32+0.502=4.8196 \mathrm{~W}
$$

So the efficiency of the convertercalculated as:

$$
\begin{gathered}
\eta=\frac{\mathrm{P}_{\text {out }}}{\mathrm{P}_{\text {out }}+\mathrm{P}_{\text {loss }}} \times 100 \% \\
\eta=\frac{160}{160+4.8196} \times 100 \%=97.07 \%
\end{gathered}
$$

\subsubsection{Losses in Conventional Hard Switching Converter}

The main switch in this converter is hard switched and the switching losses are determined utilizing the condition. The voltage over the turn amid $\mathrm{ON}$ and OFF conditions is $40 \mathrm{~V}$ and the pinnacle current is estimated to be 4A. The switching losses of the switch in customary Buck converter are:

$$
P=V_{0} \times I_{0} \times F_{s w} \times \frac{T_{o n}+T_{o f f}}{2}
$$

$$
P=40 \times 4 \times 10^{5} \times \frac{200 \times 10^{-9}+200 \times 10^{-9}}{2}=3.2 \mathrm{~W}
$$

The rms current moving through the change is estimated to be $2.82 \mathrm{Amp}$. The conduction losses are calculated as:

$$
\mathrm{P}_{\text {cond_sw }}=1.8 * 2.822 * 0.85=4.32 \mathrm{~W}
$$

The conduction losses of the diode are result of the onward voltage drop above the diode and the normal current coursing through it. The forward voltage drop is estimated to be 0.8027 Volts and the present moving through it is the load current which is 0.625 Amperes are determined utilizing.

The conduction losses of the diode can be calculated as:

The total losses in the converter are:

$$
\mathrm{P}_{\text {cond_Diode }}=\mathrm{V}_{\mathrm{F}} * \mathrm{I}_{\mathrm{D}}=0.8027 * 0.625=0.5016
$$

$\mathrm{P}_{\text {losses }}=\mathrm{P}_{\mathrm{sw}}+\mathrm{P}_{\text {cond_sw }}+\mathrm{P}_{\text {cond_ Diode }}$

$\mathrm{P}_{\text {losses }}=3.2+4.32+0.502=8.022 \mathrm{~W}$

The efficiency of the converter is calculated as:

$$
\eta=\frac{P_{\text {out }}}{P_{\text {out }}+P_{\text {loss }}} \times 100 \%
$$


J T R S International Journal of Technical Research \& Science

$$
\eta=\frac{160}{160+8.022} \times 100 \%=95.23 \%
$$

All the result computed/obtained from the comparative study are tabulated and shown in table:

Table-3.2 Comparative Study between Hard and Soft S witching

\begin{tabular}{|c|c|c|c|}
\hline S.No. & Soft Switching Specification & Hard Switching & Soft Switching \\
\hline 1. & Psw & 6.4 & 0 \\
\hline 2. & Pcond & 12.16 & 12.16 \\
\hline 3. & $\mathrm{Pd}_{\mathrm{d}}$ & 0.502 & 0.502 \\
\hline 4. & \% Efficiency & 89.34 & 92.96 \\
\hline
\end{tabular}

\section{RESULTS AND DISCUSSION}

This section shows the simulation results obtained from proposed system, which has been verified under various inputconditions and later results are verified.

4.1 Response During Constant Irradiance and Temperature at $800,25^{\circ} \mathrm{C}$

For this case reference temperature set to $25^{\circ} \mathrm{C}$ Fig. 4.1(a) and Irradiance is set to 600 Fig. 4.1(b), for both controller models. Model is simulated for $0.2 \mathrm{sec}$ and simulation plots for this case given below.

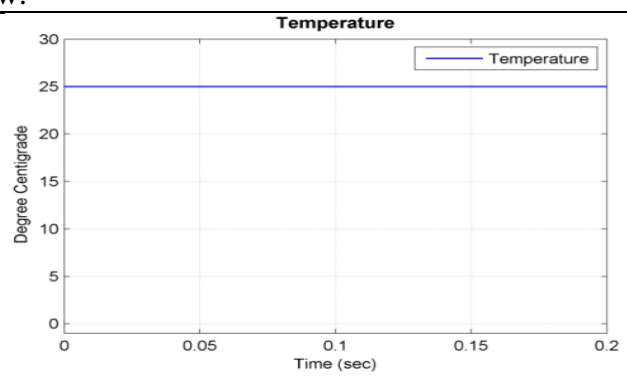

(a) Experimental waveform of Temperature

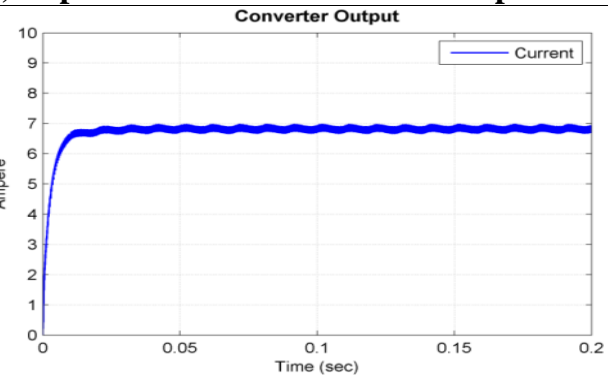

(c) Experimental Waveform of Converter Output Current

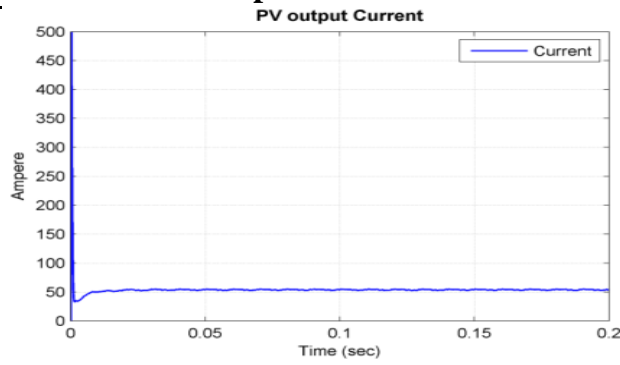

(e). Experimental waveform of PV Output Current.

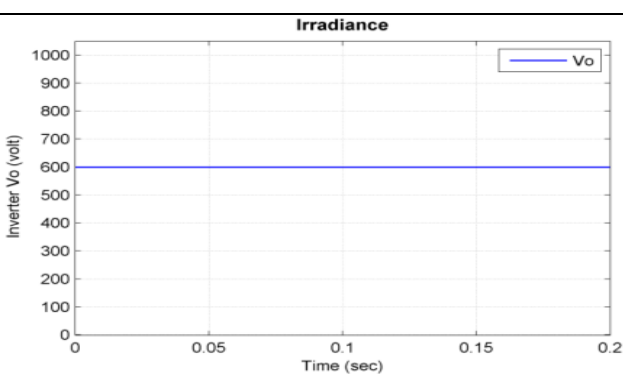

(b) Experimental waveform of Irradiance

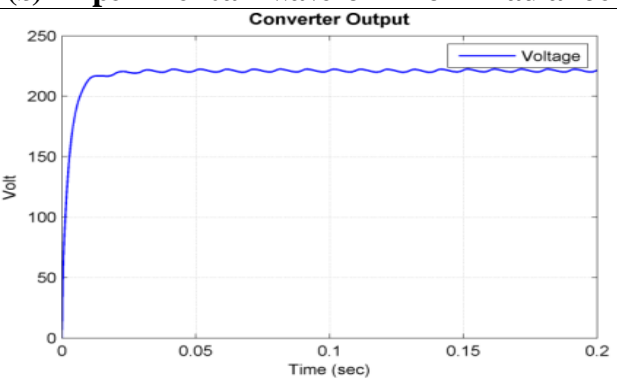

(d) Experimental Waveform of Converter
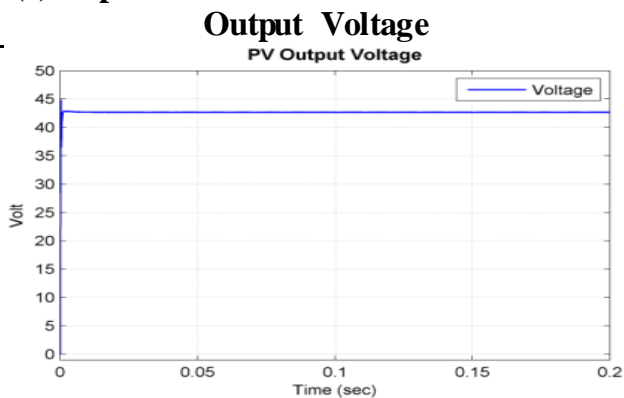

(f). Experimental waveform of PV Output Voltage. 


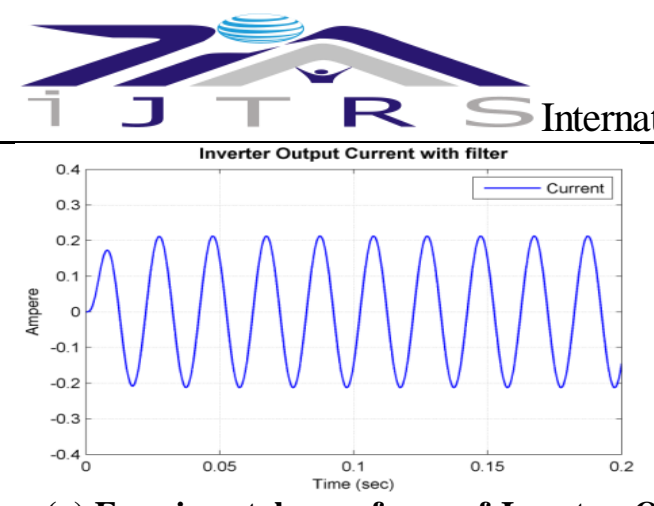

(g) Experimental waveform of Inverter Output Current with filter

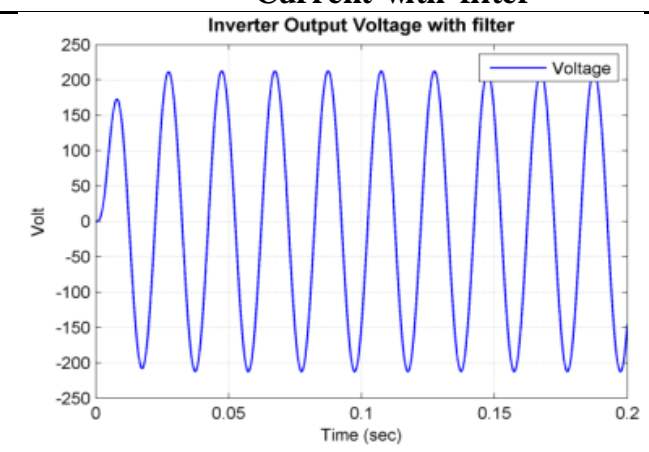

(i) Experimental Waveform of Inverter Output Voltage with Filter Pulses to Switch S1

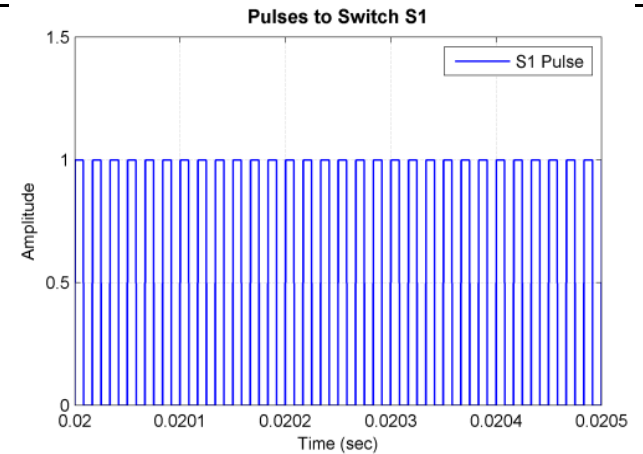

(k). Experimental waveform of Pulses to Switch S1.

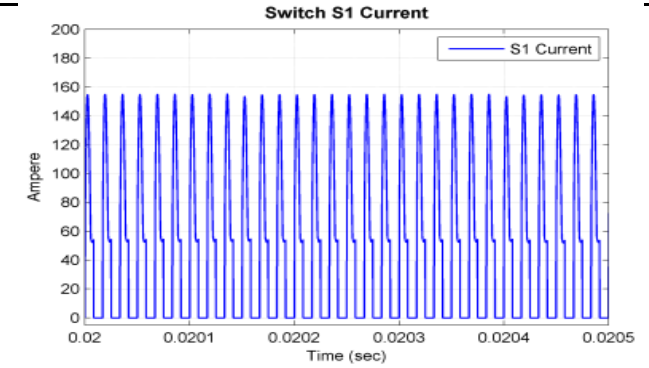

(m) Experimental Waveform of Switch S1 Current

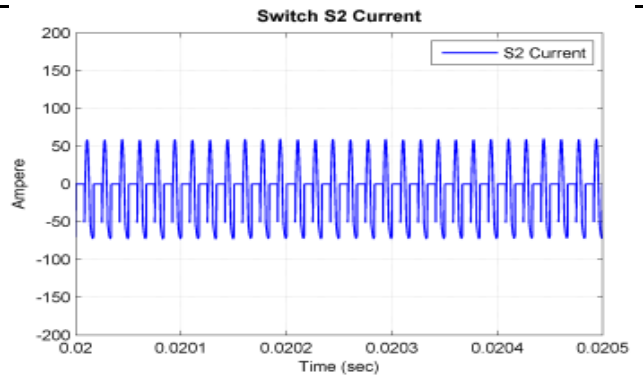

(o) Experimental waveform of Switch S2 Current

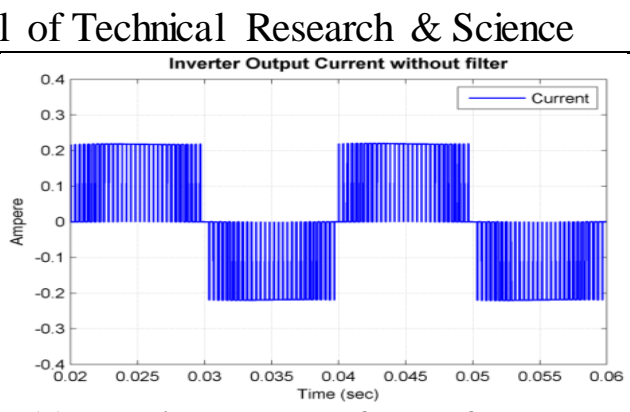

(h) Experimental waveform of Inverter Output Current without filter

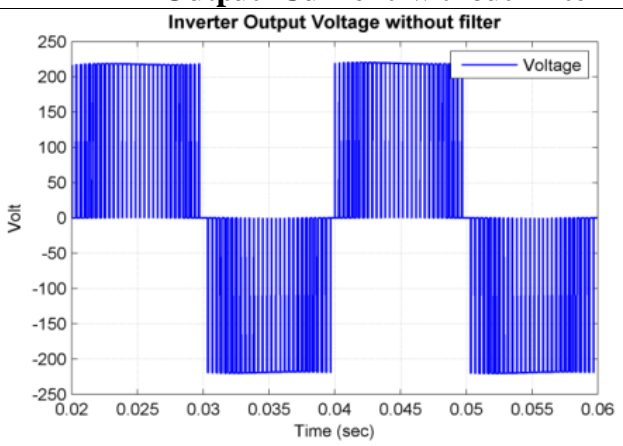

(j) Experimental Waveform of Inverter Output Voltage Without Filter

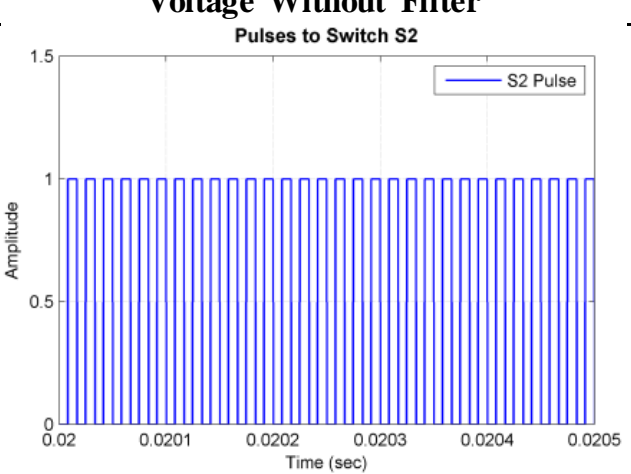

(1). Experimental waveform of Pulses to Switch S2.

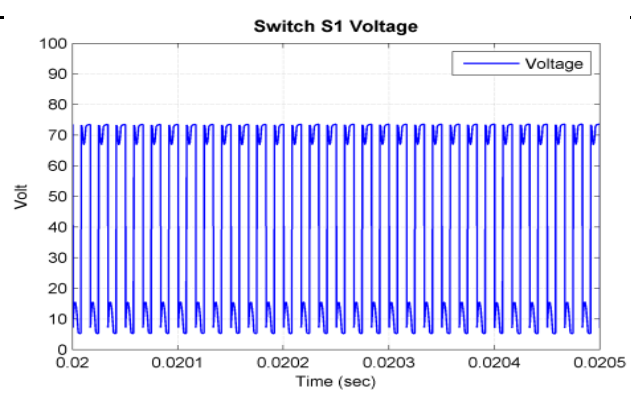

(n) Experimental Waveform of Switch S1 Voltage

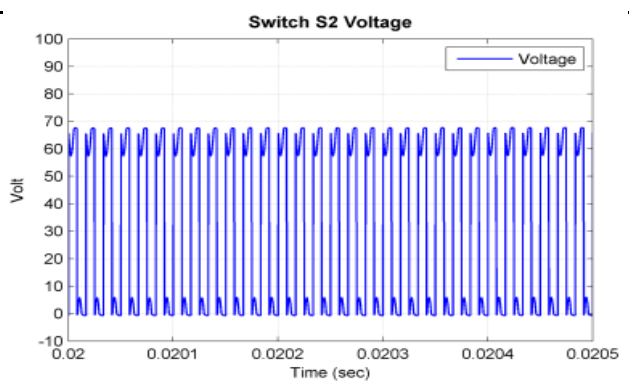

(p) Experimental waveform of Switch S2 Voltage 
7 T R S International Journal of Technical Research \& Science

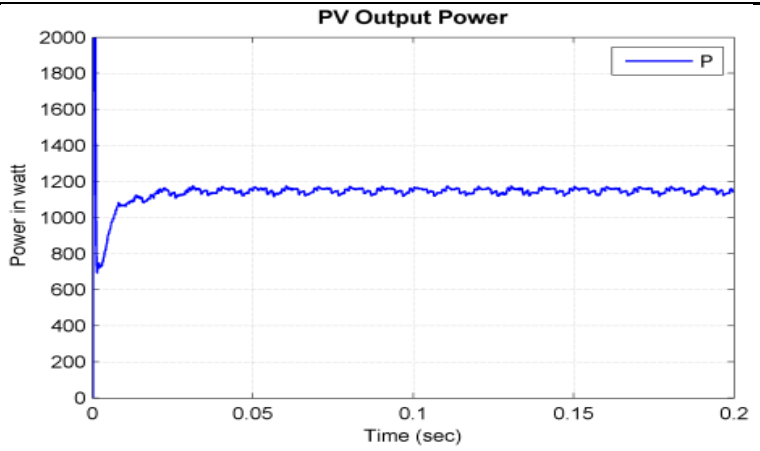

(q) Experimental waveform of PV Output Power

Fig. 4.1: Experimental Waveforms during Constant Resistive Load of $1 \mathrm{~kW}$ at 600 Irradiance and $25^{\circ} \mathrm{C}$ Temperature

4.2 Response during Constant Irradiance and Temperature at $400,25^{\circ} \mathrm{C}$.

For this case reference temperature set to $25^{\circ} \mathrm{C}$ Fig. 4.2(a) and Irradiance is set to $400 \mathrm{Fig}$. 4.2(b), Model is simulated for $0.2 \mathrm{sec}$ and simulation plots for this case given below.

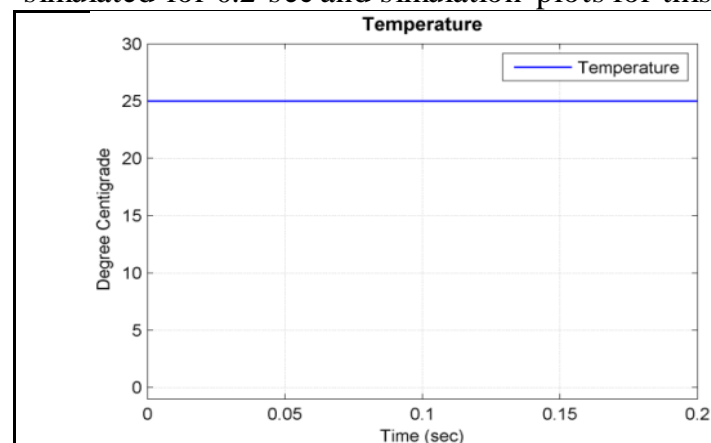

(a). Experimental Waveform of Temperature

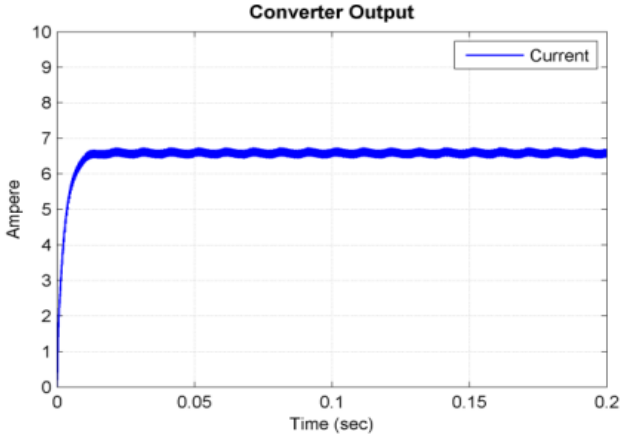

(c) Experimental Waveform of Converter

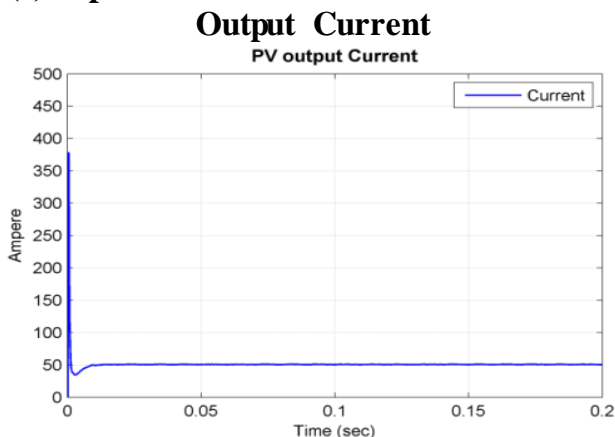

(e).Experimental waveform of PV Output Current.

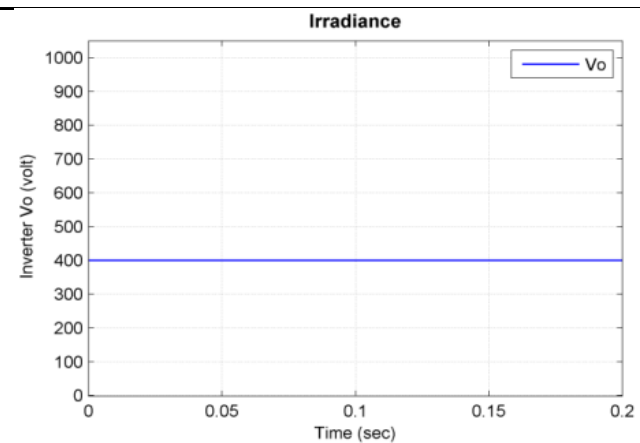

(b) Experimental Waveform of Irradiance.

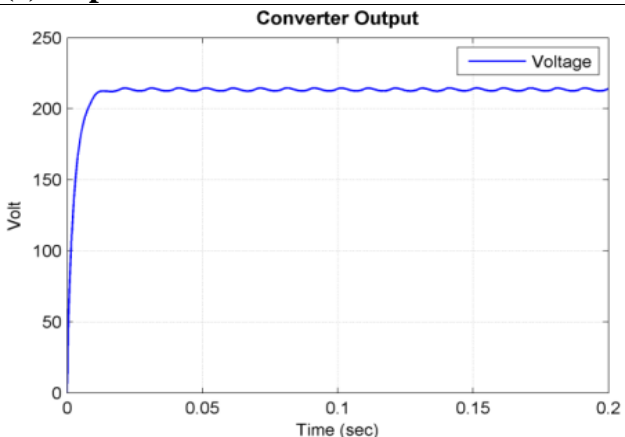

(d) Experimental Waveform of Converter Output

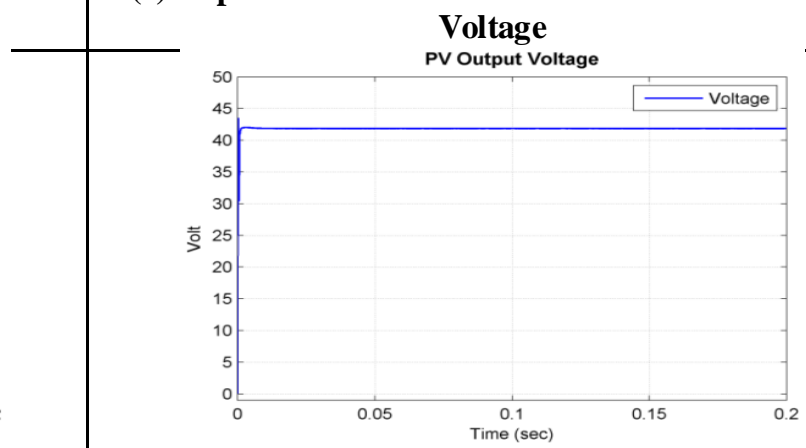

(f). Experimental waveform of PV Output Voltage. 
ᄀ T R SInternational Journal of Technical Research \& Science

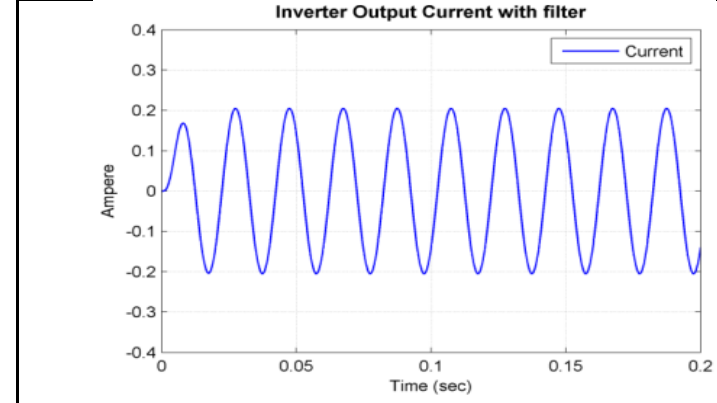

(g) Experimental Waveform of Inverter Output Current with Filter

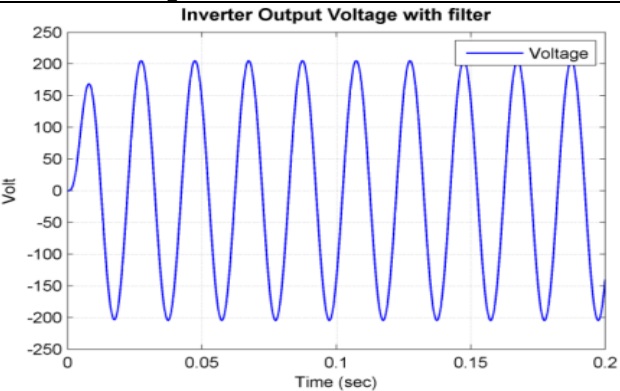

(i). Experimental waveform of Inverter Output voltage with filter.

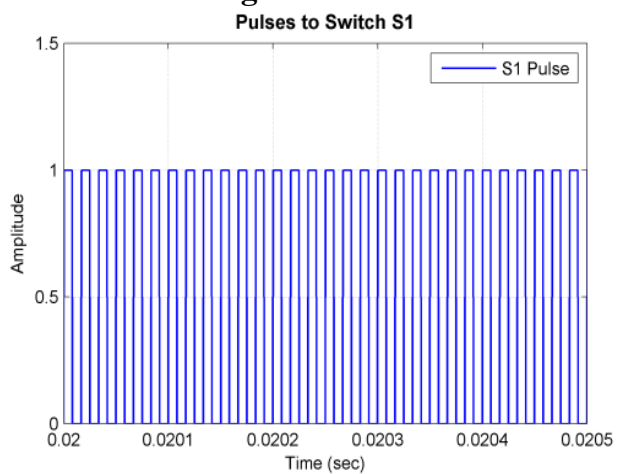

(k) Experimental waveform of Pulses to Switch S1

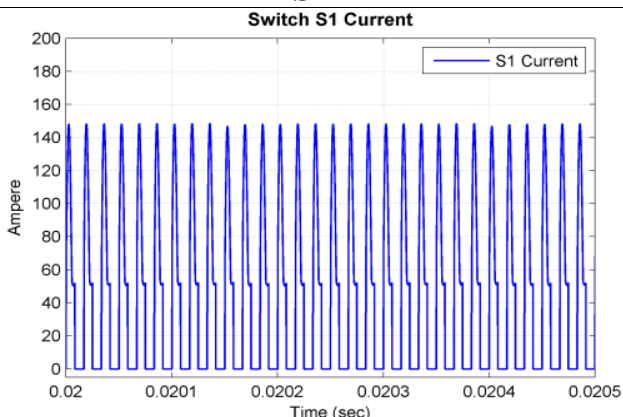

(m). Experimental waveform of Switch $\mathrm{S} 1$

Current.

Switch S2 Current

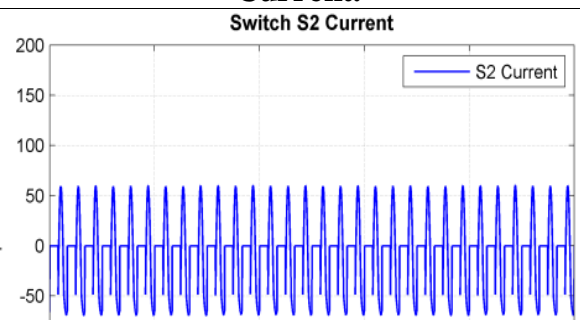

$-100$

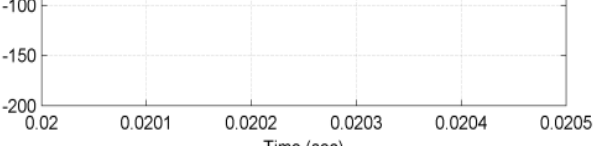

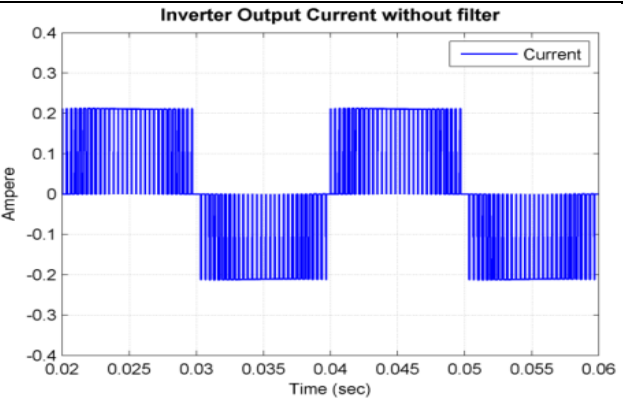

(h) Inverter Output Current without Filter

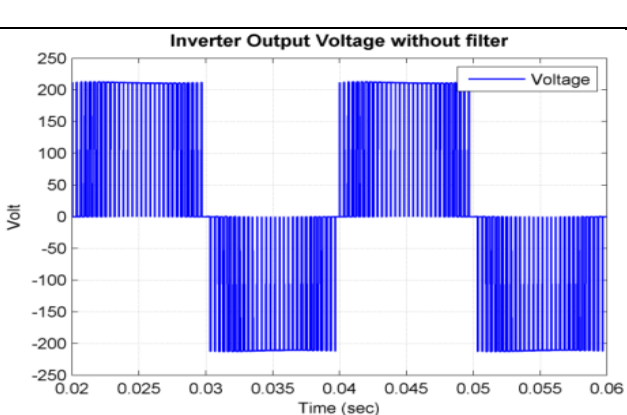

(j). Experimental waveform of Inverter Output voltage without filter.

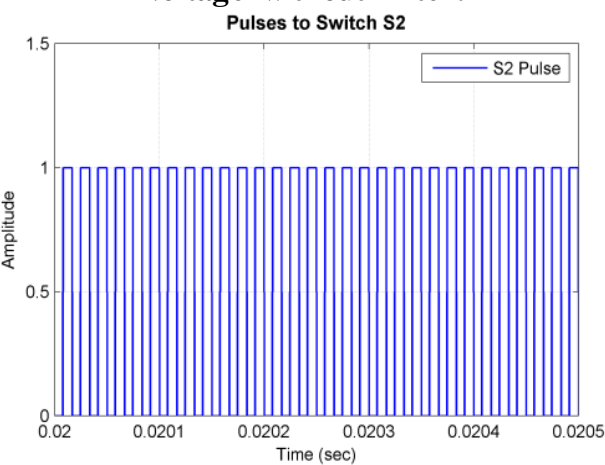

(1) Experimental waveform of Pulses to Switch S2

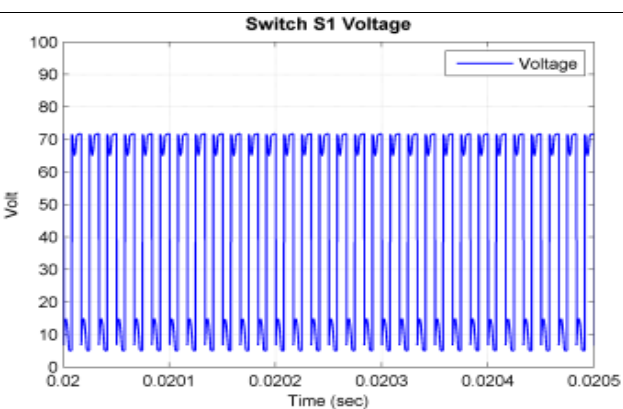

(n). Experimental waveform of Switch S1 Voltage.

DOI Number: https://doi.org/10.30780/IJTRS.V04.I08.005

$$
\text { www.ijtrs.com }
$$

www.ijtrs.org

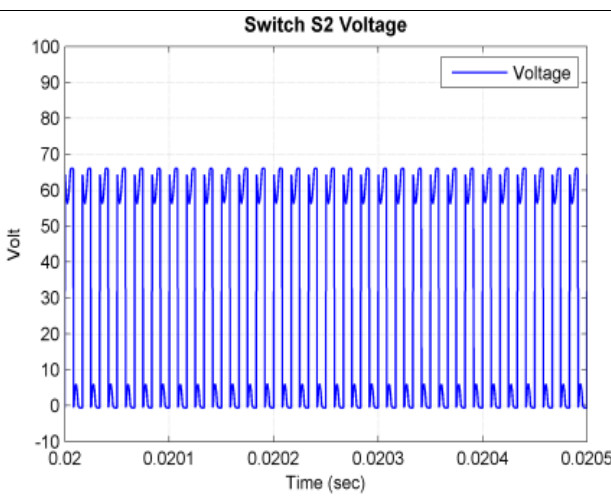


ᄀ T R SInternational Journal of Technical Research \& Science

\begin{tabular}{|l|l|} 
(o). Experimental waveform of Switch S2 & (p). Experimental waveform of Switch S2 Voltage.
\end{tabular}

Current.

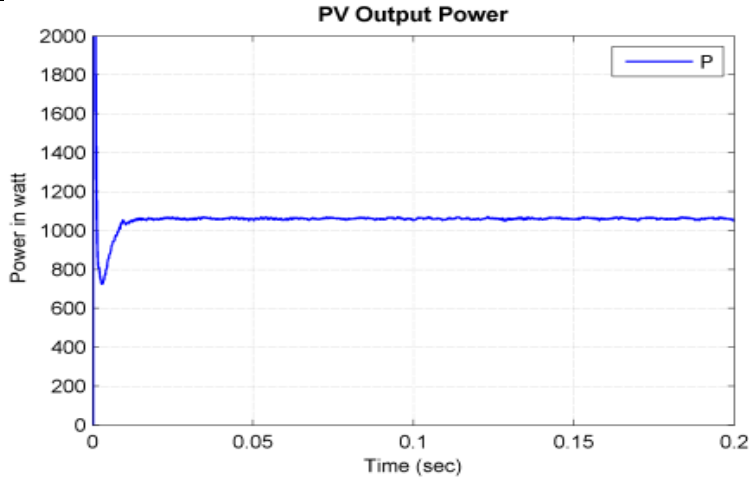

(q) Experimental waveform of PV Output Power

Fig. 4.2: Experimental Waveforms during Constant Resistive Load of $1 \mathrm{~kW}$ at 400 Irradiance and $25^{\circ} \mathrm{C}$ temperature

From test waveforms of Fig. 4.4 (g, i) a great harmony conditions among the load flows and voltages can be figured it out. Additionally, the heap voltage and current waveforms are precisely balanced.

\subsection{Response during step change in Irradiance and Temperature $25^{\circ} \mathrm{C}$}

For this case reference Irradiance is change in step and temperature is set to $25^{\circ} \mathrm{C}$. Figures 4.5 illustrate various experimental waveforms of PV output voltage, output current, output power, converter voltage, current, inverter voltage, current with and without filter, switch pulse, current voltage and inverter power.

Fig. 4.5 (a, b) shows the reference temperature is $25^{\circ} \mathrm{C}$ figure and Irradiance varies from 1000-800-600-400.

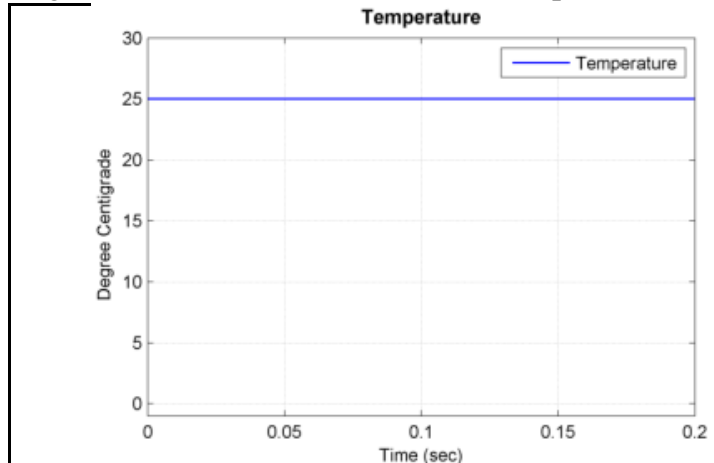

(a) Experimental waveform of Temperature

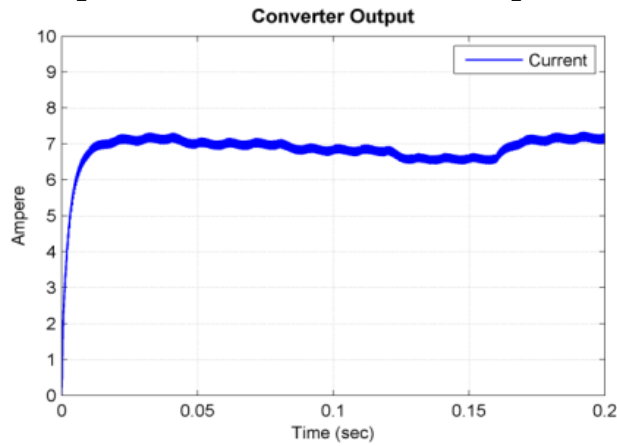

(c) Experimental waveform of Converter Output Current

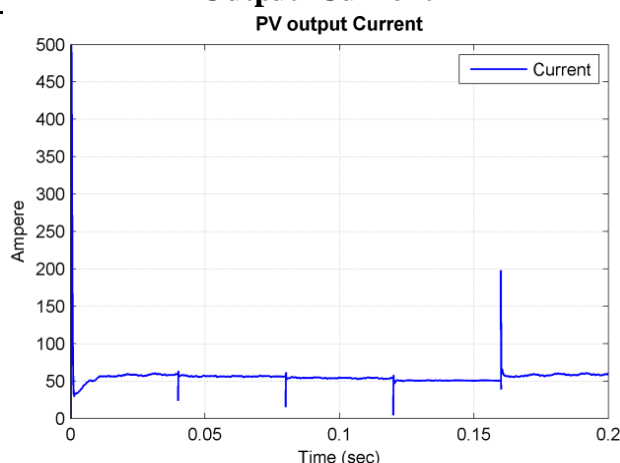

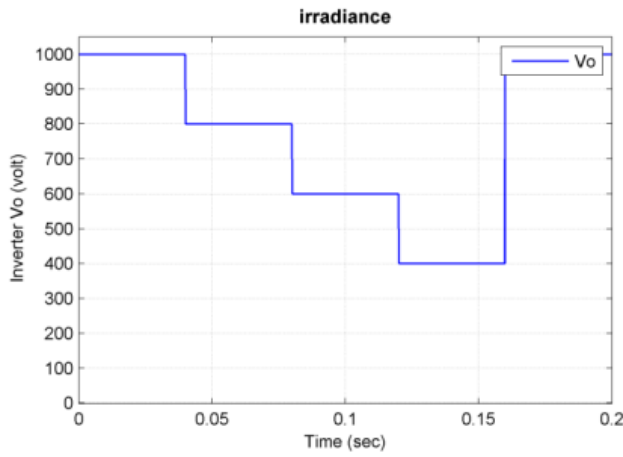

(b) Experimental wavefor $m$ of Irradiance

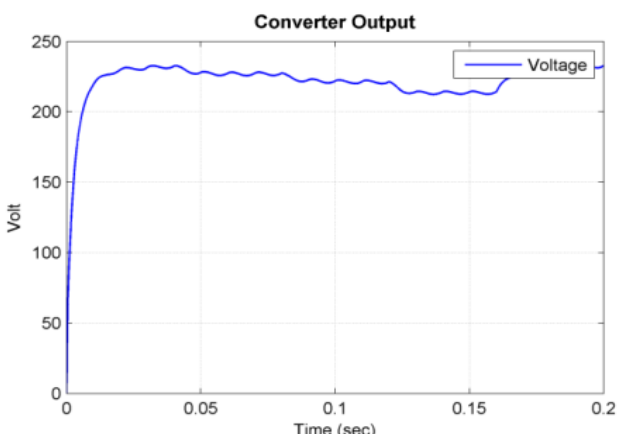

(d) Experimental waveform of Converter Output Voltage

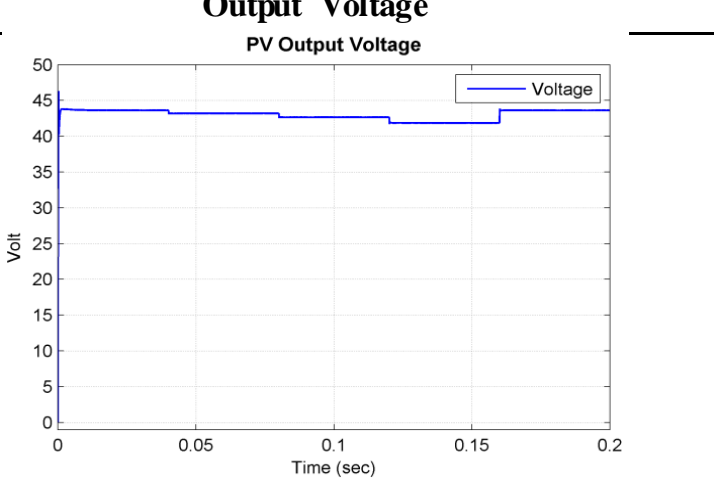

DOI Number: https://doi.org/10.30780/IJTRS.V04.I08.005

pg. 33

www.ijtrs.com

www.ijtrs.org

Paper Id: IJTRS-V4-I8-004 


\section{7 - $R$ S International Journal of Technical Research \& Science}

(e) Experimental waveform of PV Output Current 1 (f) Experimental waveform of PV Output Voltage

Fig. 4.3: Waveforms during constant resistive load of $1 \mathrm{~kW}$ at step change in Irradiance at $25^{\circ} \mathrm{C}$ temp. From the load current and voltage symphonious range examination which are appeared by Fig. 4.4(a, b), it very well may be fathomed that add up to symphonious bending (THD) of load yield current is $3.84 \%$, stack yield voltage is $4.06 \%$, which is under $5 \%$ and it is in assent with the admissible furthest reaches of IEEE 1547, IEEE-519 and IEC 61727 models.

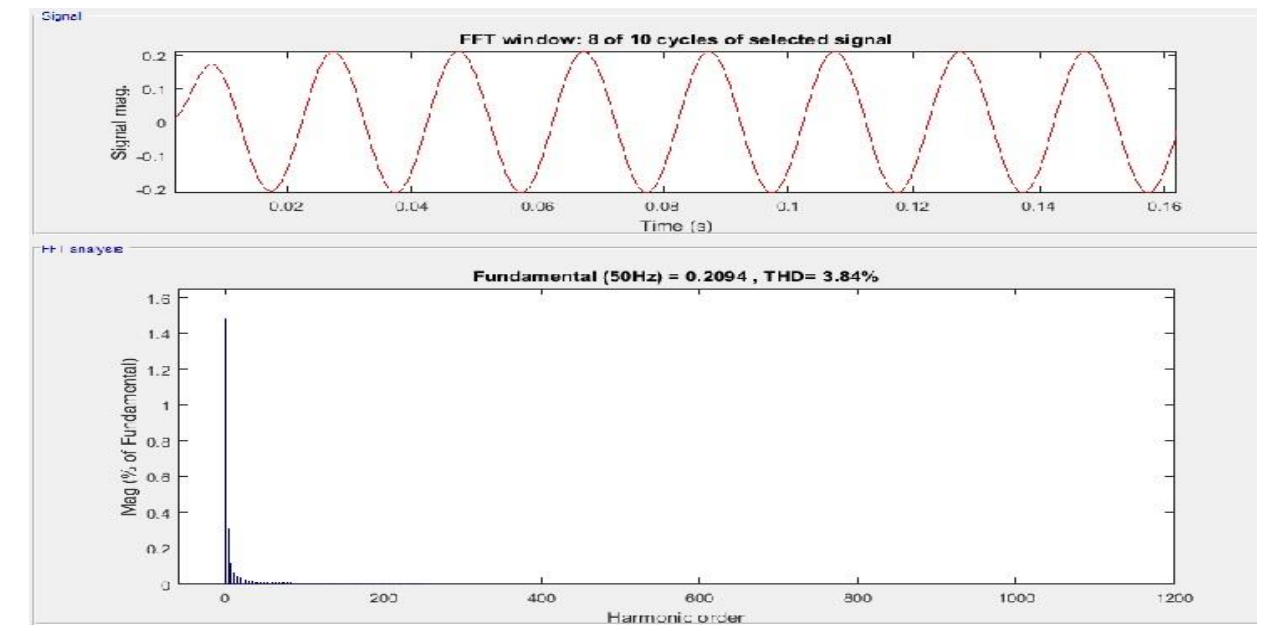

(a) Harmonic spectrum of output load current.

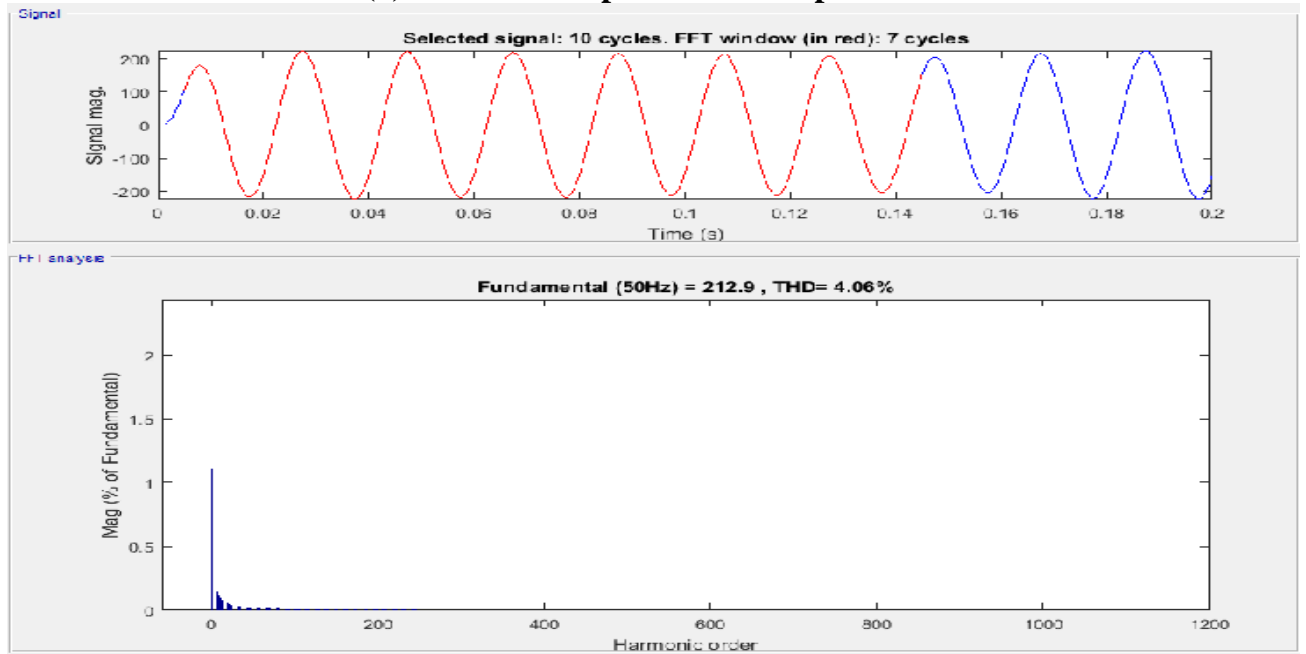

(b) Harmonic spectrum of output load voltage.

Fig. 4.4 Experimental Response of Harmonic S pectrum of Current and Voltage

From experimental results, it is examined that controller works very well and shows outstanding performance in terms of well-adjusted and regulated voltages and currents with low-THD of $3.84 \%$ as per IEEE standards.

\section{CONCLUSION}

In this work, a resonant converter for solar energy conversion system (SECS) is proposed and 200W laboratory prototype of the same has been developed. Experimental exploration of the laboratory prototype of resonant converter based SECS is carried out under different irradiance conditions and constant temperature. Various important points are concluded as:

$>$ The main switch losses of ordinary converter are a lot more noteworthy than that of delicate switching based converter. Be that as it may, the switching losses commitment of the hard switching converter overwhelms in the estimation of aggregate losses and henceforth the delicate switched full converter is observed to be more effective than the customary hard-switched converters.

$>$ It is seen that the controller effectively regulates the load voltage and frequency quite well under unbalanced and varying irradiance conditions.

$>$ The load voltage and current waveforms are reasonably balanced. Likewise, it very well may be understood that total harmonic distortion (THD) of load voltage and load current is $3.84 \%$ and $4.06 \%$ individually, which is under $5 \%$ which assent within reasonable limits as indicated by the IEEE standard 1547, IEEE-519 and IEC 61727.

$>$ During shifting irradiance condition, it is seen that load voltage is all around kept up. The trial 


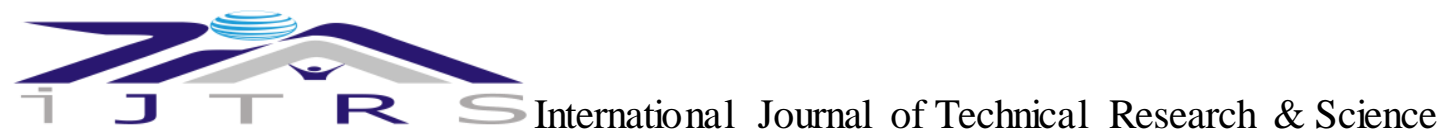

results demonstrate that the age framework can settle stack voltage under fluctuating irradiance.

\section{FUTURE WORK}

To continue and complete the work presented in this thesis, one can focus on a number of specific areas such as:

$>$ Multilevel inverter interfaced SECS can be investigated to improve the energy capture with aspect to its configuration, advanced switching strategy and developing its dynamic model.

$>$ Hybrid sensor-less control technique can be developed and examined experimentally for different operating conditions.

\section{REFERENCES}

[1] Ramon Silva-Ortigoza, at el, "DC/DC Buck Power Converter as a Smooth Starter for a DC Motor Based on a Hierarchical Control", IEEE Transactions on Power Electronics, vol.-30, no.-2, pp. 1076-1084, February 2015.

[2] Sung-Sae Lee 2014, "Step-Down Converter with Efficient ZVS Operation with Load Variation", IEEE Transactions on Industrial Electronics, vol.-61, no.-1, pp. 59, Jan. 2014.

[3] Guipeng Chen at el 2015, "Zero-Voltage-Switching Buck Converter with Low-Voltage Stress Using Coupled Inductor IET Power Electron", The Institution of Engineering and Technology, pp. $1-9,2015$.

[4] K. L. Lian , 2014, "A Maximum Power Point Tracking Method Based On Perturb-AndObserve Combined With Particle Swarm Optimization”, IEEE Journal Of Photovoltaic, vol.- 4, no.-2, pp. 626-633, March 2014.

[5] Jubaer Ahmed and Zainal Salam, "An Improved Perturb and Observe (P\&O) Maximum Power Point Tracking (MPPT) Algorithm for Higher Efficiency", Applied Energy, Elsevier, no. - $150 \mathrm{pp}$ 97-108, 2015.

[6] Abhullah M. Nomain, Hussein Marsally, "A fuzzy logic control method for MPPT of PV systems,"978-1-4673-2421-2/12/\$31.00@ 2012 IEEE.

[7] S. Soumiah Student Member, IEEE and R. Pon Vengatesh, "Performance evaluation of single switch high frequency resonant power converter for alternative energy" International Conference on Circuit, Power and Computing Technologies [ICCPCT] 2015.

[8] Ismail Aksoy, Haci Bodur, and A. Faruk Bakan, "A New ZVT-ZCT-PWM DC-DC Converter," IEEE transactions on power electronics, Vol. 25, N0. 8, August 2010.

[9] G.Moschopoulos, P.Jain, Y.Liu and Geza Joos, "A Zero Voltage Switched PWM Buck Converter with an Energy Feedforward Auxiliary Circuit," IEEE Transactions on Power Electronics, vol.14, paper 653-662, July 1999.

[10] S. Soumiah Student Member, IEEE and R. Pon Vengatesh, "Performance evaluation of single switch high frequency resonant power converter for alternative energy" International Conference on Circuit, Power and Computing Technologies [ICCPCT] 2015.

[11] Nikhil Jain, Praveen K.Jain and Geza Joos, "A Zero Voltage Transition Buck Converter Employing a Soft Switching Auxiliay Circuit with Reduced Conduction Losses," IEEE Transactions on power electronics, vol.19, no.1, January 2004.

[12] Dzung D. Nguyen at el 2009, "Performance Evaluation of Solar Photovoltaic Arrays Including Shadow Effects Using Neural Network", IEEE, pp. 3357-3362, 2009. 